\title{
Characterization of the selective in vitro and in vivo binding properties of crenezumab to oligomeric $A \beta$
}

\author{
William J. Meilandt', Janice A. Maloney ${ }^{1}$, Jose Imperio ${ }^{1}$, Guita Lalehzadeh', Tim Earr', Susan Crowell², \\ Travis W. Bainbridge ${ }^{3}$, Yanmei $\mathrm{Lu}^{4}$, James A. Ernst ${ }^{3}$, Reina N. Fuji ${ }^{5}$ and Jasvinder K. Atwal ${ }^{1 *}$
}

\begin{abstract}
Background: Accumulation of amyloid $\beta(A \beta)$ in the brain is proposed as a cause of Alzheimer's disease (AD), with $A \beta$ oligomers hypothesized to be the primary mediators of neurotoxicity. Crenezumab is a humanized immunoglobulin G4 monoclonal antibody that has been shown to bind to synthetic monomeric and aggregated A $\beta$ in vitro; however, less is known about the binding characteristic in vivo. In this study, we evaluated the binding patterns of crenezumab to synthetic and native forms of $A \beta$ both in vitro and in vivo.

Methods: Crenezumab was used to immunoprecipitate $A \beta$ from synthetic $A \beta$ preparations or brain homogenates from a PS2APP mouse model of AD to determine the forms of $A \beta$ that crenezumab interacts with. Following systemic dosing in PS2APP or nontransgenic control mice, immunohistochemistry was used to localize crenezumab and assess its relative distribution in the brain, compared with amyloid plaques and markers of neuritic dystrophies (BACE1; LAMP1). Pharmacodynamic correlations were performed to investigate the relationship between peripheral and central target engagement.
\end{abstract}

Results: In vitro, crenezumab immunoprecipitated A $\beta$ oligomers from both synthetic A $\beta$ preparations and endogenous brain homogenates from PS2APP mice. In vivo studies in the PS2APP mouse showed that crenezumab localizes to regions surrounding the periphery of amyloid plaques in addition to the hippocampal mossy fibers. These regions around the plaques are reported to be enriched in oligomeric $A \beta$, actively incorporate soluble $A \beta$, and contribute to $A \beta$-induced neurotoxicity and axonal dystrophy. In addition, crenezumab did not appear to bind to the dense core region of plaques or vascular amyloid.

Conclusions: Crenezumab binds to multiple forms of amyloid $\beta(A \beta)$, particularly oligomeric forms, and localizes to brain areas rich in $A \beta$ oligomers, including the halo around plaques and hippocampal mossy fibers, but not to vascular $A \beta$. These insights highlight a unique mechanism of action for crenezumab of engaging $A \beta$ oligomers.

Keywords: Crenezumab, Amyloid $\beta$, Alzheimer's disease, Oligomeric, Mossy fiber, Vascular amyloid

\section{Background}

Alzheimer's disease $(\mathrm{AD})$ is a progressive, fatal neurodegenerative disease that develops along a continuum, culminating in neuronal atrophy and dementia. The $\mathrm{AD}$ brain is characterized by a number of histopathologic hallmarks, including the deposition of amyloid plaques, which are composed primarily of amyloid $\beta$ (A $\beta$ ) peptides [1].

\footnotetext{
* Correspondence: atwal.jasvinder@gene.com

1 Department of Neuroscience, Genentech, Inc., 1 DNA Way, South San

Francisco, CA 94080, USA

Full list of author information is available at the end of the article
}

$\mathrm{A} \beta$ peptides can exist in multiple conformations, including soluble monomers, aggregated soluble oligomers, and insoluble fibrils [1]. While the extent to which different $A \beta$ species contribute to the pathophysiology of $\mathrm{AD}$ remains uncertain, in vitro and ex vivo evidence suggests that soluble low- $n$ molecular weight oligomers (including dimers and trimers, up to dodecamers) may be a major driver of neurotoxicity [2-7]. Furthermore, soluble $A \beta$ oligomers are thought to concentrate around the dense core of plaques, generating a neurotoxic halo that contributes to

(C) The Author(s). 2019 Open Access This article is distributed under the terms of the Creative Commons Attribution 4.0 International License (http://creativecommons.org/licenses/by/4.0/), which permits unrestricted use, distribution, and reproduction in any medium, provided you give appropriate credit to the original author(s) and the source, provide a link to the Creative Commons license, and indicate if changes were made. The Creative Commons Public Domain Dedication waiver (http://creativecommons.org/publicdomain/zero/1.0/) applies to the data made available in this article, unless otherwise stated. 
local neuritic dystrophy, synaptic loss, and neurodegeneration $[8,9]$.

Crenezumab is a humanized immunoglobulin (Ig) isotype G4 (hIgG4) monoclonal antibody (mAb) that binds to soluble forms of synthetic $A \beta$, including monomers, oligomers, and fibrils, and has an $\approx 10$-fold higher affinity for soluble oligomeric $A \beta$ than for monomeric $A \beta$ $(\operatorname{moA} \beta)(0.4-0.6$ vs $3.0-5.0 \mathrm{nM}[10,11])$. In vitro, crenezumab has been shown to block $A \beta$ aggregation, promote oligomer disaggregation, and protect neurons from oligomer-induced toxicity [11]. The IgG4 backbone also confers reduced activation of $\mathrm{Fc} \gamma$ receptors ( $\mathrm{Fc} \gamma \mathrm{Rs}$ ) compared with an IgG1 backbone and limits FcyR-mediated inflammatory activation of microglia while largely preserving FcyR-mediated microglial phagocytosis of oligomers in vitro [11]. Crenezumab's reduced effector function may lower the risk of localized microvascular damage [12], and a safety finding that has been observed as amyloid-related imaging abnormalities (ARIA) representing vasogenic edema (ARIA-E) in clinical trials with other anti-A $\beta$ mAbs on an IgG1 backbone [13-17].

The objectives of this study were to investigate the in vitro and in vivo binding characteristics of crenezumab to various forms of $\mathrm{A} \beta$ to gain a better understanding of target engagement in the brain and further elucidate crenezumab's mechanism of action.

\section{Materials and methods}

\section{Mice}

All in vivo binding studies used 6- to 12-month-old plaque-bearing male and/or female PS2APP mice on a homozygous C57BL/6 background [18, 19]. PS2APP mice co-express human APP (hAPP) with the Swedish mutation K670N/M671L and human presenilin 2 with the N141I mutation, driven by Thy1 and PrP promoters, respectively. PS2APP-green fluorescent protein (GFP) mice were generated by crossing the PS2APP mice with the Thy1_GFP M-line-a previously characterized GFP reporter line that expresses GFP in a subset of neurons [20]. PS2APP mice were crossed with the $\beta$-secretase 1 (BACE1) knockout (KO) mice [21] to generate homozygous PS2APP/BACE1 ${ }^{\mathrm{WT} / \mathrm{WT}}$ or homozygous PS2APP/ $\mathrm{BACE} 1^{\mathrm{KO} / \mathrm{KO}}$ mice. Mice were housed with a 14-h light/10$\mathrm{h}$ dark light cycle with ad libitum access to water and food. All animal experiments were approved by Genentech's Institutional Animal Care and Use Committee and comply with the Institute for Laboratory Animals' guidelines for the humane care and use of laboratory animals.

\section{In vivo dosing studies}

Transgenic PS2APP or nontransgenic (Ntg) littermates were randomized into treatment groups and received a single intravenous (i.v.) dose of either crenezumab hIgG4 $(20,80$, or $200 \mathrm{mg} / \mathrm{kg})[11,17,22]$ or control hIgG4 (anti-glycoprotein D (gD), $40 \mathrm{mg} / \mathrm{kg}$ or $100 \mathrm{mg} / \mathrm{kg}$ ) diluted in platform buffer $(20 \mathrm{mM}$ histidine, $240 \mathrm{mM}$ sucrose, $\mathrm{pH} 5.5,0.02 \%$ Tween 20) and were injected at a volume of $5 \mathrm{ml} / \mathrm{kg}$. Five to 7 days after dosing, the animals were sacrificed and terminal plasma was collected via cardiac puncture prior to perfusion with phosphatebuffered saline (PBS); the right hemibrain was removed and drop-fixed in $4 \%$ paraformaldehyde. From the left hemibrain, the hippocampus, cortex, and cerebellum were dissected, weighed, and stored at $-80^{\circ} \mathrm{C}$. PS2APPGFP-M mice were injected with a single intraperitoneal (i.p.) injection of crenezumab $(120 \mathrm{mg} / \mathrm{kg})$, and terminal plasma and brains were collected $48 \mathrm{~h}$ postdose. To determine the specificity of crenezumab's binding to oligomeric $\mathrm{A} \beta$, 6- to 7-month-old PS2APP/BACE1 $1^{\mathrm{WT} / \mathrm{WT}}$ or $\mathrm{PS} 2 \mathrm{APP} / \mathrm{BACE} 1^{\mathrm{KO} / \mathrm{KO}}$ mice were administered a single i.v. dose of crenezumab $(80 \mathrm{mg} / \mathrm{kg})$, and terminal plasma and brains were collected 7 days postdose. Mice dosed with anti-moA $\beta$ [23] received daily injections $(100 \mathrm{mg} / \mathrm{kg}$, i.p. $)$ for 5 consecutive days, and plasma and brain tissues were collected $6 \mathrm{~h}$ after the final dose. Crenezumab-treated mice received a single injection of crenezumab $(80 \mathrm{mg} / \mathrm{kg}$, i.v.) and were sacrificed 5 days postdose.

\section{Immunohistochemistry}

The right hemibrain was drop-fixed in $4 \%$ paraformaldehyde for $48 \mathrm{~h}$ and then transferred to $30 \%$ sucrose in PBS. Free-floating sagittal cryosections $(35 \mu \mathrm{m})$ of the mouse brain were washed in PBS and then PBS-Triton X100 (PBST, 0.1\%) and then blocked in PBST $(0.3 \%)$ with $5 \%$ bovine serum albumin (BSA) and incubated overnight with primary antibodies diluted in $1 \%$ BSA in PBST $(0.3 \%)$ at $4{ }^{\circ} \mathrm{C}$. Goat anti-human IgG-Alexa594 (or Alexa555, 1:100-1:500; Thermo-Fisher, Waltham, MA) was used to localize the administered human antibody. Plaques were detected using the $A \beta$ fluorescent marker methoxy-X04, and oligomeric $A \beta$ was detected with mouse anti-human A $\beta$ (mA $\beta-M$ 1:2000; Agrisera, Sweden) antibody. BACE1 was detected with rabbit antiBACE1 (D10E5, 1:1000; Cell Signaling, Danvers, MA, USA) antibody, microglia with rabbit anti-Iba1 (1:1000; Wako, Richmond, VA, USA), and dystrophic neurites with rabbit anti-lysosomal-associated membrane protein 1 (LAMP1; 1:1000; abcam, San Francisco, CA, USA).

\section{Immunoprecipitation and Western blotting}

Immunoprecipitations were carried out using synthetic preparations of $A \beta 1-42$ peptide $\left(A \beta_{42}\right)$, which was preformed into $A \beta$ oligomers, or soluble brain homogenates from PS2APP which contain endogenous $A \beta$. A $\beta$ oligomers were made by resuspending $0.5 \mathrm{mg}$ of HFIP-treated $A \beta_{42}$ (rPeptide, A-1163-1) in $450 \mu \mathrm{l}$ of $150-\mathrm{mM}$ ammonium hydroxide ( $\mathrm{pH} 10.5)$ and incubating overnight at $4{ }^{\circ} \mathrm{C} . \mathrm{pH}$ was neutralized by adding $50 \mu \mathrm{l}$ of $3 \mathrm{M}$ Tris ( $\mathrm{pH} 7.2)$. Brains 
from nontreated 13- to 16-month-old male PS2APP mice or hippocampi from crenezumab-treated PS2APP/ $\mathrm{BACE} 1^{\mathrm{WT} / \mathrm{WT}}$ and PS $2 \mathrm{APP} / \mathrm{BACE} 1^{\mathrm{KO} / \mathrm{KO}}$ mice were isolated and homogenized in 10 volumes of Tris-buffered saline (TBS) with Roche Phosphatase and Complete, Ethylenediaminetetraacetic acid (EDTA)-free, protease inhibitor cocktail tablets using a Qiagen TissueLyser II $(2 \times 3 \mathrm{~min}$ at $30 \mathrm{~Hz})$. Samples were then centrifuged at $20,000 \times g$ for $20 \mathrm{~min}$. Supernatant was collected for immunoprecipitation. The extracts were precleared with $50 \mu \mathrm{l}$ of protein G Dynabeads (Invitrogen, Waltham, MA, USA) overnight at $4{ }^{\circ} \mathrm{C}$. Five micrograms of antibody-bead complexes (gD, 6E10, $4 G 8$, crenezumab, or moA $\beta$ ) was incubated with the cleared supernatant overnight at $4{ }^{\circ} \mathrm{C}$.

The beads were washed three times with TBS. Immunoprecipitated samples run on native PAGE were eluted in $150 \mathrm{mM}$ ammonium hydroxide ( $\mathrm{pH} 10.5$ ) and neutralized with $3 \mathrm{M}$ Tris to $\mathrm{pH} 7.2$, a procedure previously described to result in high recovery of $A \beta$ complexes without changing the size forms of the eluted species [24]. Samples were run with $1 \%$ digitonin on $4-16 \%$ Novex Bis-Tris gels (Invitrogen) at $150 \mathrm{~V}$ for $115 \mathrm{~min}$. The first $30 \mathrm{~min}$ of the run contained dark blue cathode buffer $(0.02 \%$ G-250) and then replaced with light blue cathode buffer $(0.002 \%$ G-250) for the remainder of the run. Gels were soaked in $0.5 \%$ SDS for $30 \mathrm{~min}$ at $37^{\circ} \mathrm{C}$ and transferred to polyvinylidene difluoride membranes (iBlot; Invitrogen). Blots were soaked in $8 \%$ acetic acid for $15 \mathrm{~min}$ to fix the proteins and then soaked in methanol briefly to destain. Membranes were boiled for $5 \mathrm{~min}$ to increase $A \beta$ antigen exposure, blocked in 5\% milk in TBS plus Tween 20, and probed with 6E10 (human A $\beta$ 3-8, SIG-39320, Covance, Richmond, VA, USA) and 4G8 (A $\beta$ 17-24, SIG-39220, Covance) antibodies for detection of amyloid precursor protein (APP) and A $\beta$, an antibody specific for the carboxy-terminal 20 residues of APP for detection of $\alpha$ - or $\beta$-carboxy-terminal fragments (SIG39152 , Covance) or an amino-terminal-specific antibody for APP (22C11, a.a 66-81, Millipore, Bedford, MA, USA) by chemiluminescence (BioRad Gel Doc).

\section{Fluorescent microscopy}

Whole slide images are captured at $\times 20$ using a Pannoramic 250 (3D Histech, Hungary) equipped with a PCO.edge camera (Kelheim, Germany), Lumencor Spectra X (Beaverton, OR), and Semrock filters (Rochester, NY) optimized for 4'6-diamidino-2-phenylindole, dihydrochloride (DAPI), tetramethylrhodamine isothiocyanate (TRITC), and cyanine 5 (Cy5) fluorophores. Ideal exposure for each channel is determined based on samples with the brightest intensity and is set for the whole set of slides to run as a batch. Images were also captured at $\times 20$ using a Leica DM5500B light microscope using
Leica Application Suite Advanced Florescence software (LAS AF4.0). Confocal images were taken using a $\times 20$ or $\times 40$ oil objective on a Zeiss LSM800 confocal laser scanning microscope using the Zen2.3 software. Quantification of mossy fiber staining was performed by measuring integrated density from two to four sections per animal using Image (NIH).

\section{In vivo antibody pharmacokinetics $(P K)$ and $A \beta$ enzyme- linked immunosorbent assay (ELISA) measurements Tissue preparation}

Cerebellum samples were weighed and homogenized in $300 \mu \mathrm{l}$ of $1 \% \mathrm{NP}-40$ (with Roche complete ETDA-free protease inhibitor cocktail) using a Qiagen TissueLyser II $(2 \times 3 \mathrm{~min}$ at $30 \mathrm{~Hz})$. Samples were then placed on ice for $20 \mathrm{~min}$ and then centrifuged at $20,000 \times g$ for $20 \mathrm{~min}$. Supernatant was collected and stored at $-80^{\circ} \mathrm{C}$ until used for PK assay.

\section{Pharmacokinetics assays}

Antibody concentrations in mouse plasma and brain samples were measured using ELISA. NUNC 384-well Maxisorp immunoplates (Neptune, NJ, USA) were coated with $\left.\mathrm{F}(\mathrm{ab})^{\prime}\right) 2$ fragment of sheep anti-human IgG, Fc fragmentspecific polyclonal antibody (Jackson ImmunoResearch, West Grove, PA, USA) overnight at $4{ }^{\circ} \mathrm{C}$. Plates were then blocked with PBS containing 0.5\% BSA for $1 \mathrm{~h}$ at room temperature. Each antibody (control IgG and anti-moA $\beta$ and crenezumab) was used as a standard to quantify the respective antibody concentrations. After the plates were washed with PBS containing 0.05\% Tween 20 using a microplate washer (Bio-Tek Instruments, Inc., Winooski, VT), standards and samples diluted in PBS containing 0.5\% BSA, $0.35 \mathrm{M}$ sodium chloride $(\mathrm{NaCl}), 0.25 \%$ 3-[(3-Cholamidopropyl)dimethylammonio]-1-propanesulfonate hydrate (CHAPS), 5 mM EDTA, 0.05\% Tween 20, and 15 ppm Proclin were incubated on plates for $2 \mathrm{~h}$ at room temperature with mild agitation. Bound antibody was detected with horseradish peroxidase-conjugated $\mathrm{F}\left(\mathrm{ab}^{\prime}\right)_{2}$ goat anti-human IgG, Fc fragment-specific polyclonal antibody (Jackson ImmunoResearch). Finally, plates were developed using the substrate 3,3',5,5' -tetramethyl benzidine (KPL, Inc., Gaithersburg, MD, USA). Absorbance was measured at a wavelength of $450 \mathrm{~nm}$ with a reference of $630 \mathrm{~nm}$ on a Multiskan Ascent reader (Thermo Scientific, Hudson, NH, USA). Concentrations were determined from the standard curve using a four-parameter nonlinear regression program. The assay had lower limit of quantitation values of $13.7 \mathrm{ng} / \mathrm{ml}$ in the plasma and $1.37 \mathrm{ng} / \mathrm{ml}$ in the brain.

\section{Pharmacodynamics assays}

$A \beta x-40$ and $A \beta x-42$ concentrations in mouse plasma samples were measured using an ELISA similar to that 
used for the PK analysis described above. Briefly, rabbit polyclonal antibody specific for the $C$ terminus of $A \beta_{40}$ or $\mathrm{A} \beta_{42}$ (Millipore) was coated onto plates, and biotinylated monoclonal anti-A $\beta 1-16$ (6E10; Covance, Dedham, MA) was used for detection. The assay had lower limit of quantification values of $15.6-23.4 \mathrm{pg} / \mathrm{ml}$ in plasma.

\section{Statistical analysis}

One-way analysis of variance (ANOVA) followed by Tukey's multiple comparison tests or Student's unpaired $t$ test (two-sided) was performed using either Prism 6.0 (GraphPad Software, San Diego, CA, USA) or JMP12.2.0 (SAS Institute Inc., Cary, NC, USA) software.

\section{Results}

\section{Crenezumab immunoprecipitates oligomeric $A \beta$ in vitro}

To investigate crenezumab's binding to $A \beta$ oligomers, we performed immunoprecipitation experiments either with synthetic pre-oligomerized $A \beta_{42}$ preparations or with endogenous $A \beta$ from the soluble fraction of plaque-enriched PS2APP brain homogenates. Samples were separated on native nondenaturing gels, which allow aggregated oligomers to remain relatively intact. We observed that preformed $A \beta_{42}$ oligomers, but not monomers, could be specifically resolved as a high molecular weight smear on these gels (Fig. 1a). Immunoprecipitations of pre-formed synthetic $A \beta_{42}$ by crenezumab, as well as other wellcharacterized commercial pan anti-A $\beta$ antibodies (6E10 and 4G8), efficiently pulled down large oligomeric forms of $\mathrm{A} \beta(\sim 66-720 \mathrm{kDa}$, Fig. 1b). Lower molecular weight species that may represent a mixture of residual monomers or low- $n$ oligomeric forms (dimers, trimers) were also detected in the pull down. In comparison, a monomeric A $\beta$-preferring antibody (anti-moA $\beta$ ) [23] that has an $\approx 25$-fold higher affinity to monomeric $\mathrm{A} \beta$ than crenezumab and nondetectable binding to oligomers (Table 1) failed to pull down much oligomeric $A \beta$ (Fig. 1b). Isotype control antibody (anti-gD) did not engage $\mathrm{A} \beta$.

Crenezumab was also used to immunoprecipitate endogenous A $\beta$ from TBS-soluble PS2APP brain homogenates, an amyloidosis mouse model of AD that expresses mutant forms of hAPP (K670N/M671L) and presenilin-2 (PS2N141I). Samples were separated on nondenaturing gels and again showed that crenezumab, unlike moA $\beta$ or isotype control antibodies, immunoprecipitated oligomeric forms of $A \beta$ that resolved as high molecular weight oligomers (Fig. 1c). These results suggest that crenezumab is able to bind to high molecular weight $A \beta$ oligomers generated in vivo. Pan anti- $\mathrm{A} \beta$ antibodies 6E10 and 4G8 also immunoprecipitated high molecular

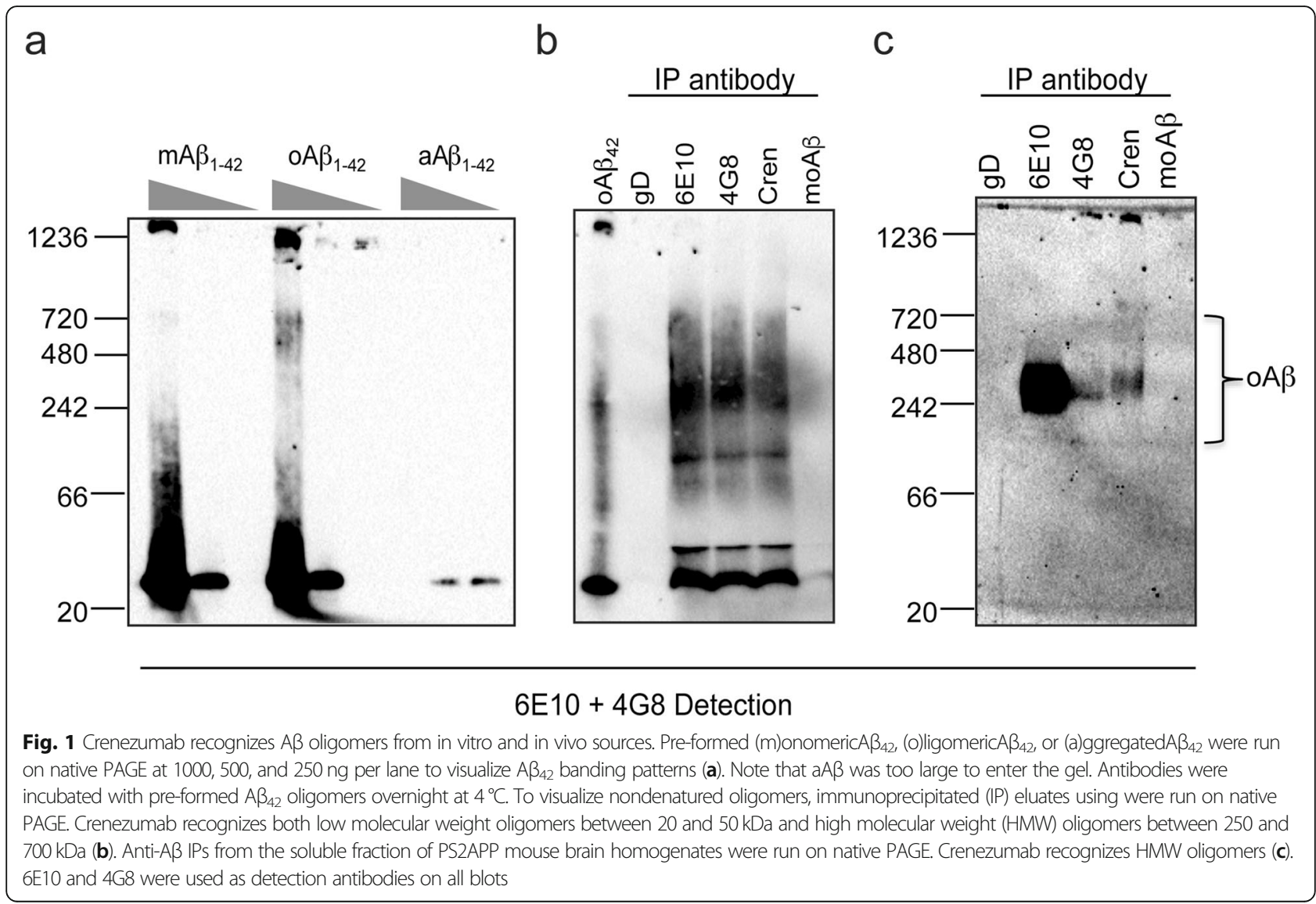


Table 1 In vivo antibody PK and in vitro biacore binding properties

\begin{tabular}{|c|c|c|c|c|c|c|c|}
\hline Molecule & $\begin{array}{l}\text { Dose (i.v.) } \\
\mathrm{mg} / \mathrm{kg}\end{array}$ & Isotype & $\begin{array}{l}C_{\max } \\
(\mu \mathrm{g} / \mathrm{ml}) \\
\end{array}$ & $\begin{array}{l}\text { AUC last } \\
(\mu \mathrm{g} / \mathrm{ml} \text { day })\end{array}$ & $\begin{array}{l}\mathrm{CL}_{\text {obs }} \\
(\mathrm{ml} / \text { day } / \mathrm{kg})\end{array}$ & $\begin{array}{l}\text { Biacore monomeric } \\
\mathrm{A} \beta \mathrm{Kd}(\mathrm{nM})\end{array}$ & $\begin{array}{l}\text { Biacore oligomeric } \\
\mathrm{A} \beta \mathrm{Kd}(\mathrm{nM})\end{array}$ \\
\hline Crenezumab & 20 & hlgG4 & 296 & 882 & 19.6 & 5 & 0.5 \\
\hline Anti-moA $\beta$ [23] & 20 & hlgG1 & 319 & 113 & 176.4 & 0.2 & Not detected \\
\hline Anti-gD & 20 & hlgG1 & 410 & 1457 & 7.6 & - & - \\
\hline
\end{tabular}

$P K$ pharmacokinetics, i.v. intravenous, $C_{\max }$ maximum concentration, $A \cup C_{\text {last }}$ area under the curve from the time of last dosing to the last measurable concentration, $C L_{\text {obs }}$ total body clearance, $A \beta$ amyloid $\beta, h l g G$ humanized immunoglobulin $G, \operatorname{mo} A \beta$ monomeric amyloid $\beta, g D$ glycoprotein $D$

weight $A \beta$ oligomers to different degrees, possibly due to recognition of distinct epitopes, which may be differentially exposed in oligomers, as well as due to differential affinities for various $A \beta$ species. Size-exclusion chromatography of TBS-soluble brain extracts confirmed that the majority of $A \beta$ species found in these brain samples was of a high molecular weight, consistent with being oligomeric in nature (i.e., eluted in or near the void volume of column, data not shown). Together, these results suggest that crenezumab is able to bind and engage a range of oligomeric $A \beta$ forms, including endogenous oligomers thought to mediate neurotoxicity in $\mathrm{AD}[2-4,8,25-29]$.

\section{In vivo immunolocalization of crenezumab to regions surrounding the dense plaque core in PS2APP transgenic mice}

To characterize the in vivo binding properties of crenezumab, we dosed PS2APP mice with a single i.v. dose of crenezumab hIgG4 $(20,80$, or $200 \mathrm{mg} / \mathrm{kg})$ or control hIgG4 (anti-gD, $100 \mathrm{mg} / \mathrm{kg}$ ) and collected brain tissue 7 days postdose for immunohistochemical analysis. Doses were selected to yield comparable exposure, on the basis of preliminary pharmacokinetic studies suggesting that systemic clearance of crenezumab in this mouse model is approximately twofold faster than that of the control antibody (Table 1). In vivo binding of crenezumab was assessed by immunostaining brain sections for hIgG, and plaques were identified by Methoxy-X04 staining. In the cortex, crenezumab localized to the periphery of amyloid plaques, and little to no binding to the dense core of the plaque was observed; control IgG4 binding was minimal and showed little to no specificity in plaque-containing regions (Fig. 2a-d). The halo staining of crenezumab to plaques was prominent throughout the brain but highest in regions that started to deposit plaques earliest (i.e., the subiculum and amygdala). Immunostaining of crenezumab around plaques in the amygdala, for example, was robust and tended to concentrate to regions of the plaque not surrounded by Iba1+ microglia (Fig. 2e), suggesting that oligomeric $A \beta$, being detected by crenezumab, may accumulate in regions near the plaque where microglia are absent, in a so-called hot-spot [30].
Soluble oligomeric forms of $\mathrm{A} \beta$ are considered more neurotoxic than dense core plaques $[1-3,5,7,8,31,32]$ and seem to play a greater role in $A \beta$-induced neurotoxicity, including synaptic spine loss and the formation of neuritic dystrophies $[8,26,33,34]$, which are large swellings of axons/neurites that occur in close proximity to amyloid plaques [34, 35]. Numerous proteins have been found to accumulate in dystrophic neurites, including LAMP1, ubiquitin, synaptophysin, APP, and BACE1 [30, 36, 37]. Accumulation of BACE1 in dystrophic neurites is thought to contribute to increased $A \beta$ production locally near plaques [36]. To determine whether crenezumab binding to the halo region around plaques associates with markers of neuritic dystrophies, we performed confocal imaging of co-stained sections from in vivodosed animals for crenezumab and BACE1 (Fig. 2f) or LAMP1 (Fig. 2g) and found the crenezumab signal was localized proximal to both BACE1 and LAMP1, indicating a close spatial relationship between the $A \beta$ forms that are bound by crenezumab surrounding the plaque core. It is unlikely that the in vivo-dosed crenezumab is able to enter the intracellular space of the dystrophic neurite; rather, crenezumab appears to be decorating the outside of these structures marked by BACE1 or LAMP1. Moreover, in PS2APP mice neuronally expressing GFP to visualize dendritic processes, crenezumab binding was found to concentrate within regions surrounding methoxy-X04-stained plaques that were devoid of dendritic processes (Fig. $2 \mathrm{~h}-\mathrm{k}$ ), reflecting $\mathrm{A} \beta$ induced neurotoxicity.

Together, these results suggest that crenezumab is selectively binding, in vivo, to peripheral regions around the plaque core where there is believed to be a high concentration of soluble oligomeric $A \beta$ that contributes to neuronal and synaptic dysfunction.

\section{In vivo-dosed crenezumab does not bind to vascular amyloid}

Similar to parenchymal plaques, amyloid deposits in the brain vasculature are often observed in patients with AD. These vascular deposits are recapitulated in PS2APP mice and were readily detectable by methoxy-X04 staining. However, we found no evidence of vascular amyloid binding by crenezumab even when PS2APP mice were dosed 


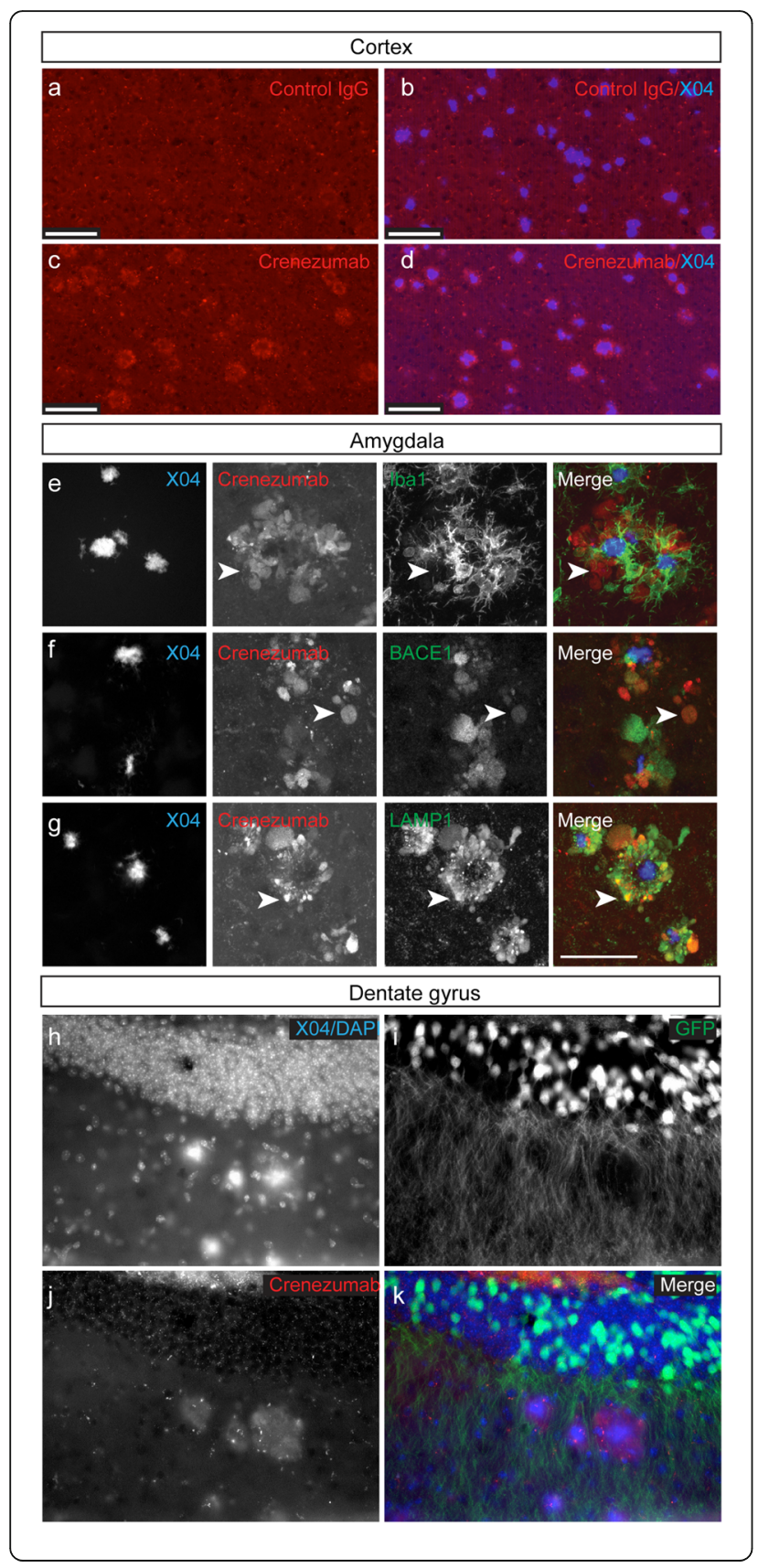

Fig. 2 In vivo-dosed crenezumab binds in a halo around amyloid plaques and to dystrophic neurites in PS2APP mice. In vivo-dosed crenezumab (200 mg/kg, i.v.) was visualized 7 days postdose with anti-hlgG-Alexa594 antibody (red), and plaques were stained with methoxy-X04 (blue). Representative epifluorescent images of plaqueassociated halo of staining by crenezumab alone (c) and with plaques (d) in the cortex. Note the absence of staining in the control-injected (control lgG, gD) mice around plaques (a, b). In the amygdala (e-g), confocal z-stacked images show crenezumab binding was prominent around the core of the plaque but in regions not covered by microglia (e) (labeled with Ibal, green). This staining pattern was reminiscent of dystrophic neurites and was confirmed by co-staining of crenezumab ( $80 \mathrm{mg} / \mathrm{kg}$, i.v., red) with markers of dystrophic neurites including BACE1 (green, $\mathbf{f}$ ) and LAMP1 (green, $\mathbf{g})$. Arrowheads indicate example regions of overlap. In vivo-dosed crenezumab (j, k, red, $120 \mathrm{mg} / \mathrm{kg}$, IP) was localized to regions between methoxy-X04-labeled plaques (h, $\mathbf{k}$, blue) and GFP-labeled dendrites (i, $\mathbf{k}$, green) in the dentate gyrus of PS2APP-GFP (line M) mice (2 days postdose). Scale bar, $200 \mu \mathrm{m}$ (a-d) and $50 \mu \mathrm{m}(\mathbf{e}-\mathbf{g})$

up to $200 \mathrm{mg} / \mathrm{kg}$ (Fig. 3a-c). The lack of crenezumab binding to the cerebral amyloid angiopathy is consistent with its lack of binding to the parenchymal plaque core, both structures that are detected by methoxy-X04 staining. This suggests that crenezumab does not interact with this form of highly aggregated fibrillar $A \beta$. These findings may have important relevance to the reported low incidence of ARIA-E in crenezumab-treated patients [11, 17, 22].

\section{In vivo-dosed crenezumab binds to mossy fiber axons in the hippocampus}

In vivo dosing of crenezumab led to the novel finding that prominent immunoreactivity was observed in the mossy fiber tract of the hippocampus in PS2APP mice (Fig. 4a, b). The mossy fibers are the axons of the dentate granule cells that terminate in the hilus and in the stratum lucidum of the CA3 region [38-40]. Mossy fiber binding was specific to crenezumab, as no staining was observed in the control IgG-injected animals (Fig. 4a). Crenezumab binding to the mossy fibers was dose dependent and significantly greater than that in vehicle and control IgG-injected animals (Fig. 4a, b). The lack of methoxy-X04 staining in the mossy fibers suggests that crenezumab's binding was not to fibrillar $A \beta$, but likely to soluble $A \beta$ species.

Neuronal BACE1 initiates the processing of APP and is hypothesized to facilitate $A \beta$ overproduction in $A D$ affected brains $[36,37]$. BACE1 is expressed in neurons throughout the brain and is highly expressed in the mossy fiber axons of the hippocampus [36, 37, 41], suggesting that a high level of APP processing could lead to $\mathrm{A} \beta$ accumulation, driving oligomer generation in this region of the hippocampus. To confirm that the crenezumab binding to the mossy fibers was dependent on $A \beta$ and not binding to APP or soluble APP fragments, we crossed the PS2APP mice with BACE1 KO mice. 

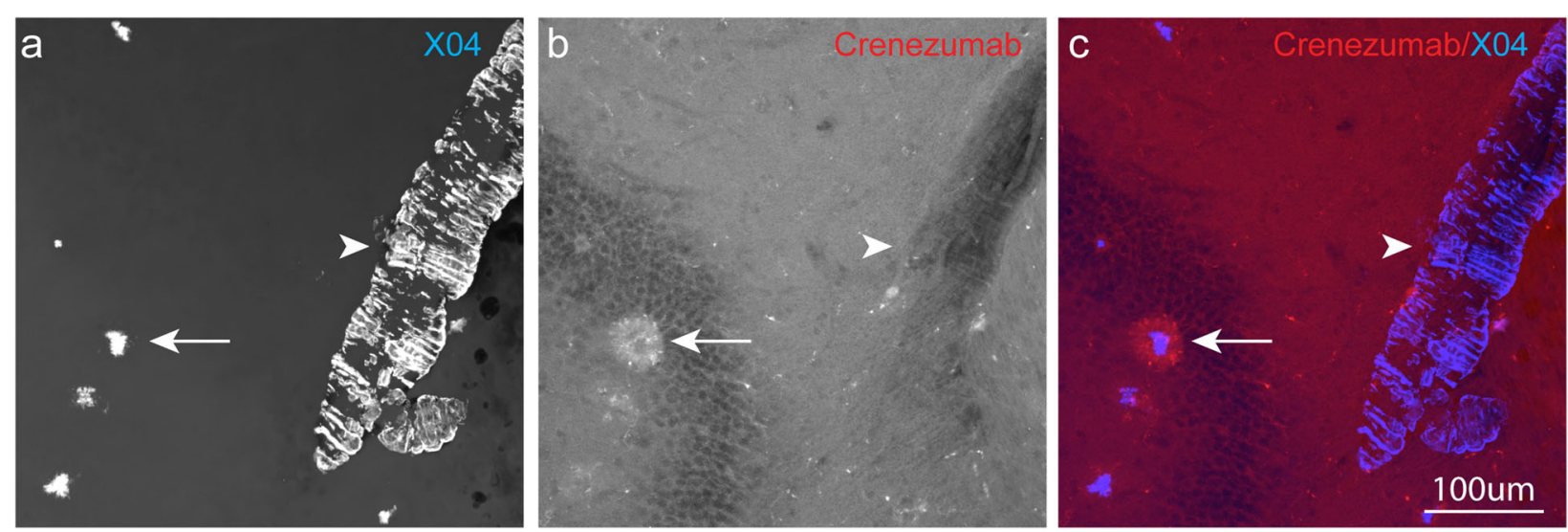

Fig. 3 In vivo-dosed crenezumab does not bind to vascular amyloid in PS2APP mice. Representative confocal $\times 40$ images (z-stack maximum projection) of parenchymal amyloid plaques (arrow) and vascular amyloid (arrowhead) stained with methoxy-X04 (a, c, blue). Note the selective staining of in vivo-dosed crenezumab (200 mg/kg, i.v.) (b, c, red) to the peri-plaque region and the absence from the vascular amyloid. Scale bar, $100 \mu m$

PS2APP/BACE1 $1^{\mathrm{WT} / \mathrm{WT}}$ and PS2APP/BACE1 ${ }^{\mathrm{KO} / \mathrm{KO}}$ mice were dosed with crenezumab $(80 \mathrm{mg} / \mathrm{kg})$, and brain samples were collected 7 days postdose. First, we observed that in vivo-dosed crenezumab localized strongly to mossy fiber tracts with positive immunostaining for BACE1, suggesting that crenezumab is immunodecorating the mossy fiber axons of PS2APP/BACE1 ${ }^{\text {WT/WT }}$ mice (Fig. $5 \mathrm{a}-\mathrm{C}$ ). Interestingly, crenezumab binding often appeared as bright puncta in the CA3 region; we speculated that crenezumab may concentrate around the large mossy fiber presynaptic terminals $[38,41]$. Next, when compared with PS2APP/BACE1 ${ }^{\mathrm{WT} / \mathrm{WT}}$ mice (Fig. 5d), crenezumab binding to the mossy fibers was markedly reduced in PS2APP/BACE1 ${ }^{\mathrm{KO} / \mathrm{KO}}$ mice (Fig. 5e), indicating that binding is dependent on BACE1 activity, thus indeed predominantly $A \beta$ dependent. Quantification of the mossy fiber binding relative to surrounding neuropil (Fig. 5g) did show, however, that low levels of crenezumab binding remained in the mossy fibers of the $\mathrm{PS} 2 \mathrm{APP} / \mathrm{BACE} 1^{\mathrm{KO} / \mathrm{KO}}$ mice, which could represent binding to APP or to a low level of $A \beta$ produced by alternative proteases, since this signal was completely absent in the Ntg mice (Fig. 5f). We also confirmed by Western blot that the BACE1 deletion blocked any

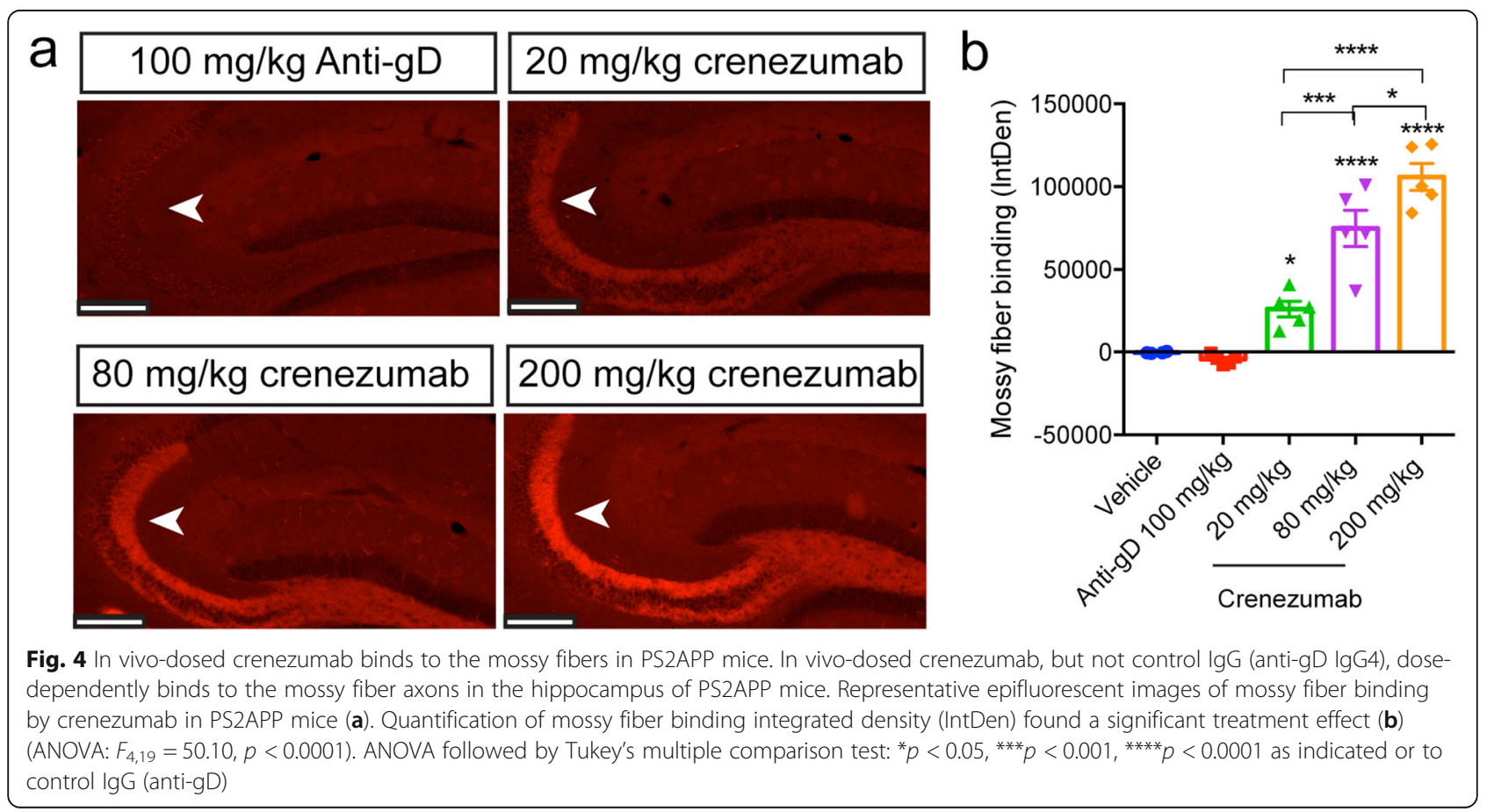



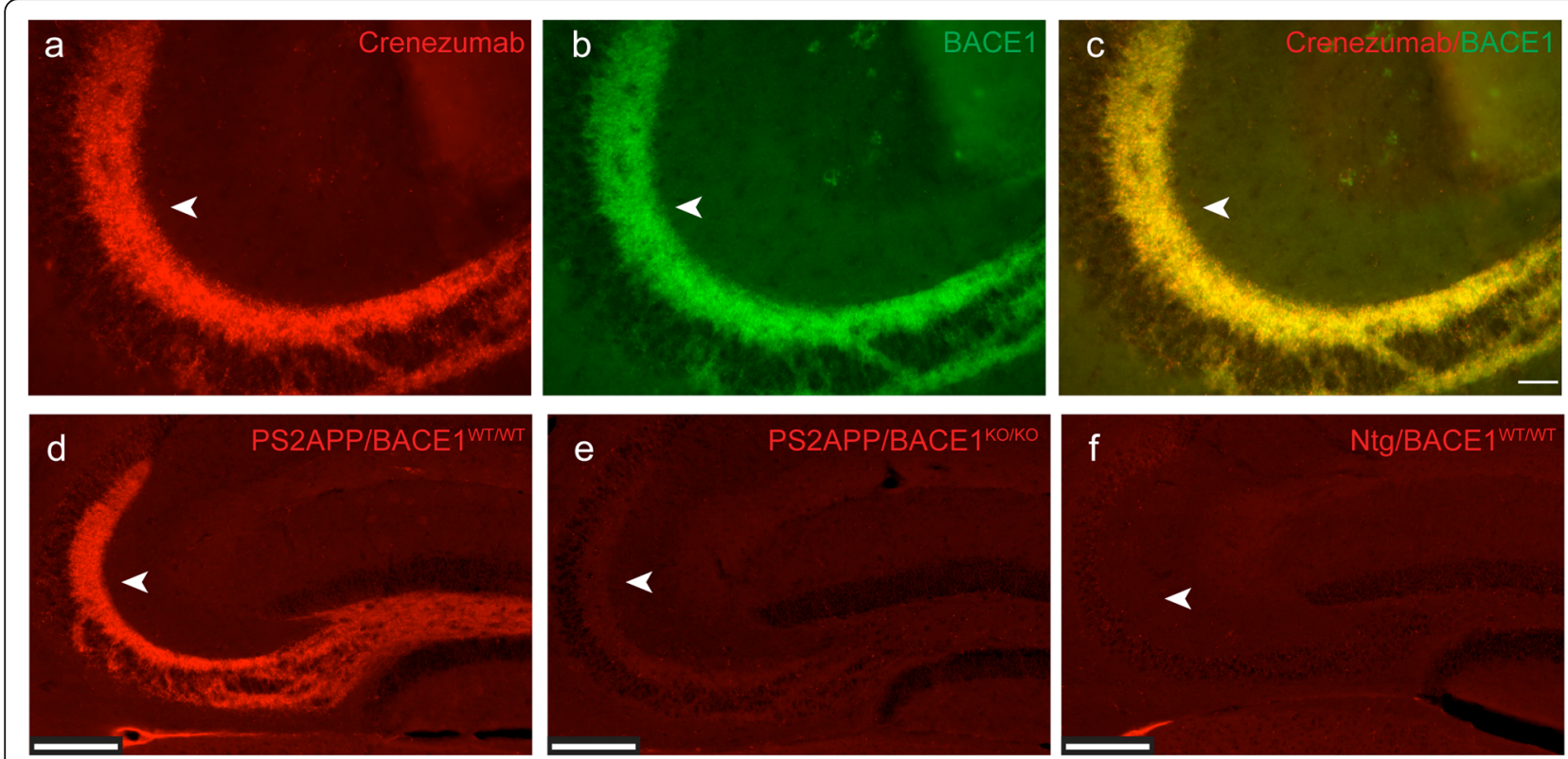

g

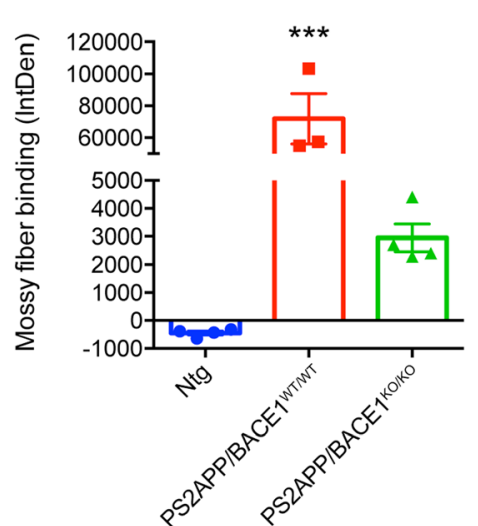

h

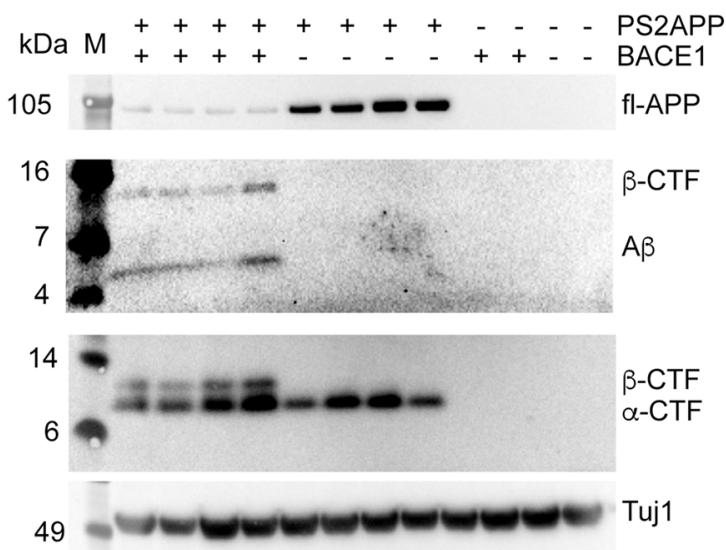

Fig. 5 Crenezumab binding to the hippocampal mossy fibers is $A \beta$ dependent. Representative epifluorescent images of in vivo-dosed crenezumab $(80 \mathrm{mg} / \mathrm{kg}$ ) binding to the mossy fibers (a) of PS2APP mice (arrows). Immunostaining for BACE1 shows strong binding in the mossy fibers (b) that overlap with crenezumab staining (c, merge). Scale bar $=50 \mu \mathrm{m}$. In vivo-dosed crenezumab $(80 \mathrm{mg} / \mathrm{kg})$ staining to the mossy fibers in the PS2APP/BACE1 ${ }^{\text {WTNTT }}$ mice (d) was nearly completely absent in PS2APP/BACE1 ${ }^{\mathrm{KO} / \mathrm{KO}}$ (e) compared with Ntg/BACE1 ${ }^{\text {WTMT }}$ (f) mice. Scale bar, $200 \mu \mathrm{m}$. $\mathbf{g}$ Significant differences in mossy fiber binding were found between the groups (ANOVA: $F_{2,8}=29.16, p<0.001$ ) $n=3-4 /$ group. ANOVA followed by Tukey's multiple comparison test. ${ }^{* *} p<0.001$ versus all others. $\mathbf{h}$ Western blots of full-length/soluble APP and AB (detected by $4 \mathrm{G} 8$ and 6 E10) and $\alpha / \beta-C$-terminal fragment (detected by SIG-39152) from soluble hippocampal TBS homogenates from PS2APP/BACE1 ${ }^{\text {WTMTT, }}$ PS2APP/BACE ${ }^{\mathrm{KO} / \mathrm{KO}}$, and Ntg/BACE1 ${ }^{\mathrm{WT} / \mathrm{WT}}$ mice. $\beta$-Tubulin (Tuj1) was used as a loading control. M, molecular weight marker

detectable APP processing and $A \beta$ production in the PS2APP mice. We found that BACE1 deletion caused an elevation in full-length/soluble APP and a complete loss of BACE1 cleavage products, including $\beta-C$-terminal fragment and $A \beta$ (Fig. 5h).

We next wanted to determine whether the mossy fiber binding represented soluble monomeric $A \beta$ or oligomeric $\mathrm{A} \beta$ binding by crenezumab. To investigate this further, we dosed PS2APP mice with either crenezumab or a monomer-preferring anti-moA $\beta$ antibody. Preliminary studies (Table 1 ) found that the anti-moA $\beta$ antibody had fast clearance $(176.4 \mathrm{ml} /$ day $/ \mathrm{kg})$ compared with crenezumab $(19.6 \mathrm{ml} /$ day $/ \mathrm{kg})$ following a single dose in PS2APP mice. Therefore, to achieve comparable exposure levels in the brain, we needed to dose the PS2APP mice daily with the anti-moA $\beta(100 \mathrm{mg} / \mathrm{kg})$ for 5 consecutive days and collect the brain and plasma samples $6 \mathrm{~h}$ after the final dose. Crenezumab $(80 \mathrm{mg} / \mathrm{kg})$ or an isotype control antibody $(40 \mathrm{mg} / \mathrm{kg})$ was given once, and tissues were collected 5 days postdose. At the end of the study, peripheral antibody concentrations of anti-moA $\beta$ were approximately twofold higher than crenezumab (Fig. 6a), due to the more frequent dosing. In the brain, both crenezumab and anti-moA $\beta$ had similar exposures, as desired (Fig. 6b); 

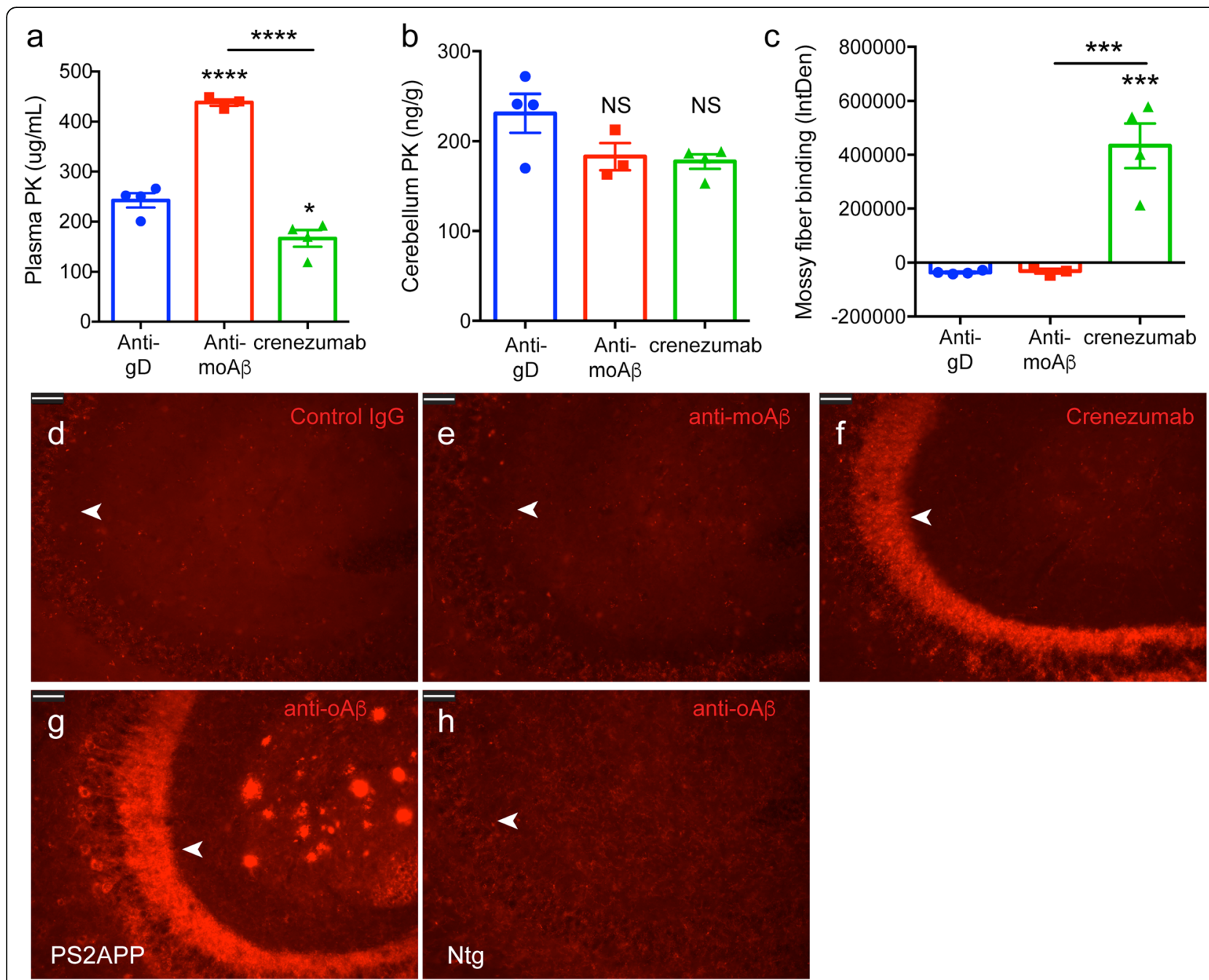

Fig. 6 In vivo-dosed crenezumab binds to (o)ligomeric $A \beta$, not to (mo)nomeric $A \beta$, in the hippocampal mossy fiber tract. Plasma and cerebellum PK levels $6 \mathrm{~h}$ after the final day of dosing $(100 \mathrm{mg} / \mathrm{kg}$ daily for $5 \mathrm{~d})$ with an anti-moA $\beta(n=3)$ or 5 days after a single injection of control IgG (anti-gD $40 \mathrm{mg} / \mathrm{kg}, n=4)$ or crenezumab $(80 \mathrm{mg} / \mathrm{kg}, n=4)$ in PS2APP mice. ANOVA found a significant difference in plasma PK levels (a) $\left(F_{2,8}=86.90, p<0.0001\right)$ but not in the cerebellum (b; not significant [NS]). Quantification (c) and representative epifluorescent images (d-f) of mossy fiber binding by crenezumab but not by control IgG or moA $\beta$ antibodies. ANOVA found a significant difference in binding $\left(F_{2,8}=26.84, p<0.001\right)$. Representative images of ex vivo OA 3 staining in the mossy fibers (arrows) of PS2APP mice $(\mathbf{g})$, but not in Ntg mice (h), using an anti-oA $\beta$ antibody (mab-M). Scale bar, $50 \mu \mathrm{m}$. ANOVA followed by Tukey's multiple comparison test: ${ }^{*} p<0.05,{ }^{* * *} p<$ $0.001,{ }^{* * *} p<0.0001$ as indicated or to control lgG

however, only crenezumab showed the characteristic mossy fiber binding unlike anti-moA $\beta$ (Fig. 6c-f). Together, these results suggest that in vivo-dosed crenezumab binds to oligomeric $A \beta$, not monomeric $A \beta$.

To further confirm that the mossy fibers contained oligomeric $A \beta$, we immunostained brain sections from PS2APP and Ntg mice ex vivo with an antibody preferential for oligomeric $A \beta(m A b-M)$ and found prominent staining in the mossy fibers of only PS2APP mice (Fig. 6g) but not Ntg (Fig. 6h). This result is consistent with previous studies in another AD mouse model using a different oligomeric $A \beta$ antibody [37]. Overall, these findings suggest that crenezumab is binding to soluble oligomeric $A \beta$, not to monomeric $A \beta$ in the mossy fiber tract.

\section{Measures of peripheral target engagement correlate with crenezumab binding to the mossy fibers}

To investigate crenezumab's engagement of soluble $A \beta$ species in the periphery, we measured changes in soluble $\mathrm{A} \beta$ in the plasma of crenezumab-treated PS2APP mice. We found a significant dose-dependent elevation in plasma $A \beta_{40}$ (Fig. 7a) and $A \beta_{42}$ (Fig. 7b) with crenezumab treatment compared with vehicle and control IgG-injected animals. This is consistent with reported elevations in plasma and cerebrospinal fluid (CSF) $A \beta$ following 
a

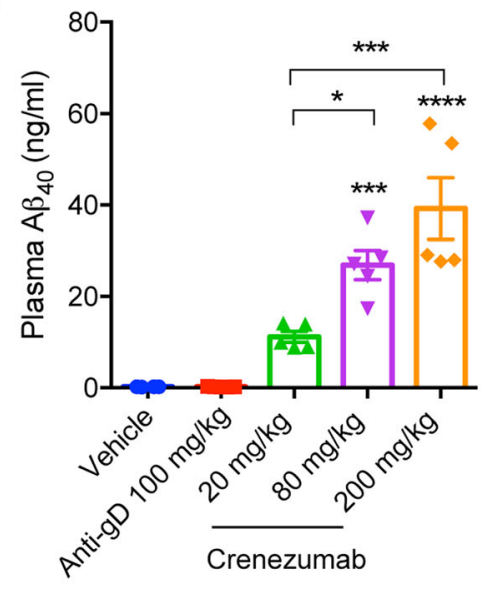

C

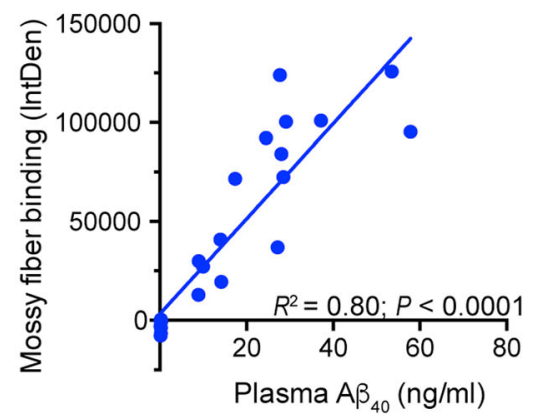

b
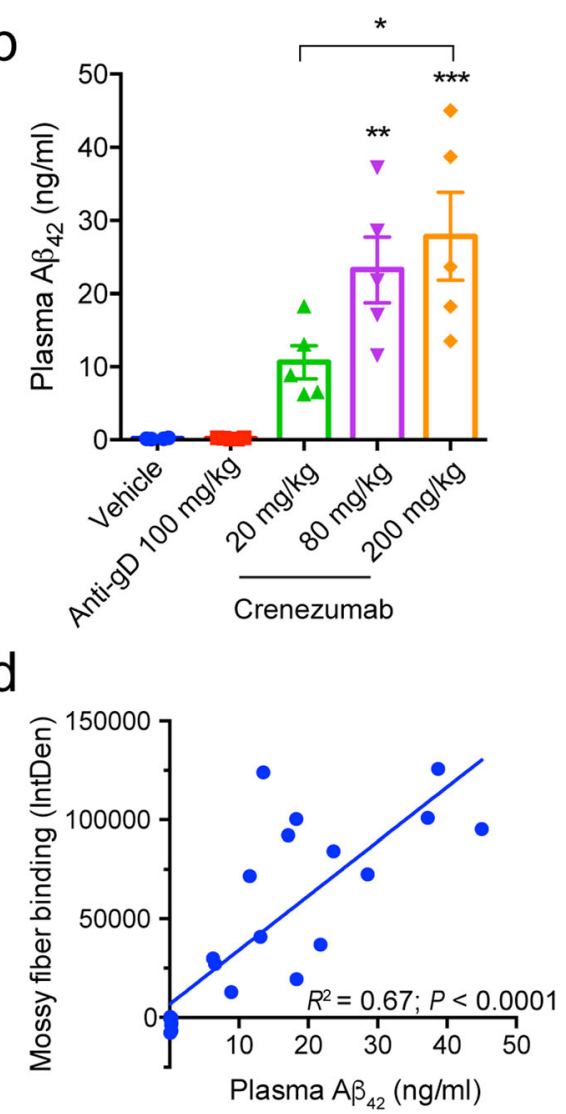

Fig. 7 In vivo crenezumab-mediated target engagement correlates between the periphery and brain. Significant elevations in plasma $A \beta_{40}(\mathbf{a})$ (ANOVA: $F_{4,19}=23.43, p<0.0001$ ) and $A \beta_{42}(\mathbf{b})$ (ANOVA: $F_{4,19}=12.08, p<0.0001$ ) were found 7 days after crenezumab treatment. A significant correlation was observed between the elevations in plasma $A \beta_{40}$ (c) $\left(R^{2}=0.08, p<0.001\right)$ and $A \beta_{42}(\mathbf{d})\left(R^{2}=0.67, p<0.001\right)$ and crenezumab mossy fiber binding (see Fig. 4) by linear regression. $N=5$ /group. ANOVA followed by Tukey's multiple comparison test: ${ }^{*} p<0.05$, ${ }^{* *} p<0.01$, ${ }^{* * *} p<0.001,{ }^{* * *} p<0.0001$ as indicated or to control lgG

crenezumab treatment in patients $[11,17,22]$. In the plasma, this likely represents stabilization of the $A \beta /$ antibody complex, leading to reduced clearance rates of $A \beta$. However, it is not known if any relationship exists between such peripheral target engagement and central (brain) target engagement by crenezumab. To investigate this in our AD mouse model, we looked to see if there was any correlation between plasma $A \beta$ and mossy fiber binding. Here, we found a significant positive correlation between plasma $A \beta$ elevations and crenezumab mossy fiber binding for both $\mathrm{A} \beta_{40}$ (Fig. 7c; $R^{2}=0.80, p<0.0001$ ) and $\mathrm{A} \beta_{42}$ (Fig. $7 \mathrm{~d} ; R^{2}=0.67, p<0.0001$ ), suggesting that measures of peripheral target engagement (plasma A $\beta$ elevations) can correlate with in vivo brain target engagement (mossy fiber binding). These results also indicate that crenezumab binding to soluble $A \beta$ in the plasma does not hinder the ability of antibody to bind to $A \beta$ in the brain even with doses as high as $200 \mathrm{mg} / \mathrm{kg}$ in this mouse model.

\section{Discussion}

The search for an effective treatment for AD has proven to be enormously challenging. Several therapeutic approaches targeting amyloid have been, or are being, tested in the clinic, including passive immunization with anti-A $\beta$ antibodies [29], inhibition of $A \beta$ production by blocking BACE1 activity [42-44], and modulation of gamma-secretase activity $[44,45]$. As the disease etiology continues to be investigated, it has become clear that $A \beta$ can exist in multiple forms and conformations (monomer, oligomer, and insoluble fibrils/plaque) and that anti- $\mathrm{A} \beta$ antibodies directed against these different forms of $A \beta$ may have varying therapeutic benefit.

In this study, we aimed to further characterize the binding properties of our anti-A $\beta$ IgG4 mAb crenezumab both in vitro and in vivo. In vitro binding studies with synthetic and brain-derived oligomeric preparations confirm crenezumab's ability to bind and immunoprecipitate multiple forms of $A \beta$, including both low (dimers and trimers) and 
high ( - $700 \mathrm{kDa})$ molecular weight oligomers in addition to monomers. In vivo dosing experiments using the PS2APP mouse, a transgenic mouse model of AD, demonstrated that crenezumab binding localized to brain areas with putative high concentrations of $A \beta$ oligomers, the form of $A \beta$ thought to be the most neurotoxic $[2-4,25]$. These areas included the periphery of amyloid plaques and hippocampal mossy fibers. Crenezumab's staining pattern is markedly different from plaque-preferring anti$\mathrm{A} \beta$ antibodies, such as aducanumab and gantenerumab, that have been reported to show strong immunostaining within the dense core, not the periphery, of the amyloid plaque but no mention of or reported binding to the mossy fibers $[16,46]$. This could be due to potential differences in each anti- $\mathrm{A} \beta$ antibody's in vivo $\mathrm{A} \beta$ binding profile and mechanism of action; however, we cannot rule out differences in the types of $\mathrm{A} \beta$ species generated in by different transgenic hAPP mouse models used.

Crenezumab binding to the halo surrounding plaques is consistent with findings that there is a synaptotoxic halo in close proximity surrounding plaque cores (within $50 \mu \mathrm{m}$ ) that consists of $\mathrm{A} \beta$ oligomers [8, 9, 47, 48]. Indeed, PS2APP mice have significantly reduced synaptic spine densities within this halo $[19,49]$, and we now have shown that crenezumab selectively binds within regions of dendritic loss surrounding the plaque core. Crenezumab was also found to bind to regions surrounding amyloid plaques that are not covered by Iba1+ microglia. These regions are reported to be "hot-spots" that actively incorporate soluble $A \beta$ and contribute to $A \beta$-induced neurotoxicity and axonal dystrophy [30]. As noted earlier, soluble oligomeric forms of $A \beta$ are associated with greater neurotoxicity compared with dense core plaques [2-4, 25]. Crenezumab binding was also found to associate closely with regions of neuritic dystrophy (identified by staining for LAMP1 and BACE1). Both LAMP1 and BACE1 are known to accumulate in dystrophic neurites, perhaps indicating dysfunctional axonal transport and function [30, 36, 37]. The accumulation of BACE1 to dystrophic neurites is hypothesized to contribute to local APP processing and soluble $\mathrm{A} \beta$ production that "feed" the plaques and contribute to synaptic dysfunction [36, 37]. Crenezumab binding and immunodecorating to regions of dystrophic neurites suggests that this may also be a region of concentrated oligomeric $\mathrm{A} \beta$ accumulation. For instance, blocking the continued production of soluble $A \beta$ in plaque-bearing transgenic hAPP mice using a tet-off system reduced soluble levels of oligomeric $A \beta$, ameliorated synaptic loss near plaques, and reduced neuritic dystrophies in addition to improving cognitive function [50], all of which were further enhanced with anti-A $\beta$ antibody treatment [51].

In vivo dosing studies also unveiled the novel mossy fiber binding by crenezumab. This binding was dose dependent and specific. Results showing a lack of
methoxy-X04 and anti-moA $\beta$ antibody binding to this region, although binding by another oligomer-preferring antibody was observed, provide further evidence that crenezumab binding was likely to oligomeric $A \beta$. The presence of high BACE1 expression in the mossy fibers, again, suggests a region of concentrated oligomeric $A \beta$ production. In addition, crenezumab staining was markedly reduced in PS2APP-BACE1 ${ }^{\mathrm{KO} / \mathrm{KO}}$ mice, indicating that the mossy fiber staining was indeed an interaction with soluble extracellular $A \beta$ and not with full-length or soluble APP.

Identifying biomarkers in the CSF or periphery that are translatable to in vivo target engagement in the brain for crenezumab, or any other anti-A $\beta$ antibody, will be of critical importance for clinical trial investigations. We have found that elevations in plasma $A \beta_{40}$ and $A \beta_{42}$ levels following crenezumab treatment in PS2APP mice recapitulate elevations observed in crenezumab-treated patients $[11,17,22]$, likely representing a change in clearance properties of $A \beta$ once bound by crenezumab given the otherwise rapid clearance of $A \beta$ alone $[52,53]$. The elevation in PS2APP plasma A $\beta$ levels significantly correlated with the intensity of crenezumab's mossy fiber binding, suggesting that peripheral evidence of target engagement correlates with target engagement in the brain. We can also conclude that the peripheral target engagement by crenezumab did not act as a "sink," thereby reducing the amount of free antibody able to enter the brain and bind $A \beta$.

One of the most commonly reported adverse events associated with anti-A $\beta$ antibodies in clinical trials is ARIA-E [29, 54-56]. Crenezumab, to date, has been shown to have a low occurrence of ARIA in clinical trials $[11,17,22]$ which may be partially attributed to its reduced effector function on an IgG4 backbone [11]. Anti- $\mathrm{A} \beta$ antibodies that reportedly bind to insoluble aggregated forms of $A \beta$ have a higher incidence of ARIA in clinical trials $[16,57,58]$ and, when injected into mouse models of $\mathrm{AD}$, bind to vascular amyloid in addition to the fibrillar core of amyloid plaques [16, 59]. In this study, we identified that crenezumab does not bind to vascular amyloid or to the fibrillar dense core of plaques, suggesting that vascular amyloid consists mostly of fibrillar forms of $A \beta$, which stain with methoxy-X04, and not of oligomeric $A \beta$. In conjunction with the reduced effector function of crenezumab on microglial activation, lack of vascular $A \beta$ binding in these preclinical models $[13-15,17]$ may help explain the reduced occurrence of ARIA and ARIA-E observed in the clinical trials of crenezumab [11, 17, 22].

Exploratory post hoc analyses of phase II clinical trials in mild to moderate $\mathrm{AD}$ patients showed that the higher of two crenezumab doses tested (i.e., i.v. infusions of 15 $\mathrm{mg} / \mathrm{kg}$ every 4 weeks vs subcutaneous injections of 300 
mg every 2 weeks) reduced cognitive decline in the milder subset of patients (Mini-Mental State Exam 22-26) $[17,22]$, suggesting that earlier treatment and greater brain exposure of crenezumab may provide clinical benefit. In addition, a recent publication [60] showed that crenezumab was able to significantly reduce oligomeric $A \beta$ levels measured in the CSF from this same patient population. However, pivotal phase III trials (CREAD, CREAD2) in prodromal to mild AD patients were recently discontinued following a pre-planned interim analysis in CREAD that indicated crenezumab was unlikely to meet the primary endpoint, even though patients were given four times the phase II dose of crenezumab $(60 \mathrm{mg} / \mathrm{kg}$, i.v. every 4 weeks). Biomarker analyses of the phase III studies are ongoing, and thus, engagement of oligomeric $A \beta$ and its relation to cognitive improvement is yet to be confirmed.

\section{Conclusions}

Crenezumab's selective binding to oligomeric versus monomeric $\mathrm{A} \beta$ species, both in vitro and in vivo, is a key component of crenezumab's mechanism of action and has major implications for its differentiation from other therapeutic anti-A $\beta$ monoclonal antibodies. In vivo localization of crenezumab binding in PS2APP mice to regions hypothesized to be rich in oligomeric $A \beta$, including the halo around amyloid plaques, dystrophic neurites, and hippocampal mossy fibers, suggests that crenezumab may interfere with oligomeric-mediated pathogenic signaling by engaging and possibly neutralizing oligomeric forms of $\mathrm{A} \beta$. The absence of crenezumab binding to the dense core of plaques and to vascular amyloid, together with the reduced effector function of its IgG4 backbone, is consistent with a lack of plaque removal or increased incidence of ARIA-E in patients treated with crenezumab.

\footnotetext{
Abbreviations

$A \beta$ : Amyloid $\beta_{;} A \beta_{40}$ : Amyloid $\beta$ 1-40 peptide; $A \beta_{42}$ : Amyloid $\beta$ 1-42 peptide; AD: Alzheimer's disease; ANOVA: Analysis of variance; APP: Amyloid precursor protein; ARIA: Amyloid-related imaging abnormalities; ARIA-E: Amyloidrelated imaging abnormalities representing vasogenic edema; $A \cup C_{\text {last }}$ : Area under the curve from the time of last dosing to the last measurable concentration; BACE1: Beta-secretase 1; BSA: Bovine serum albumin; CHAPS: 3-[(3-Cholamidopropyl)dimethylammonio]-1-propanesulfonate hydrate; $\mathrm{CL}_{\mathrm{obs}}$ : Total body clearance; $C_{\text {max }}$ : Maximum concentration; CSF: Cerebrospinal fluid; dA $\beta$ : Dimeric amyloid $\beta$;

EDTA: Ethylenediaminetetraacetic acid; ELISA: Enzyme-linked immunosorbent assay; FcyRs: Fcy receptors; GFP: Green fluorescent protein; hAPP: Human amyloid precursor protein; hlgG: Humanized immunoglobulin G; hlgG4: Humanized immunoglobulin isotype G4; HMW: High molecular weight; Ig: Immunoglobulin; IntDen: Integrated density; i.p.: Intraperitoneal; i.v.: Intravenous; KO: Knockout; LAMP1: Lysosomal-associated membrane protein 1; mAb: Monoclonal antibody; moA $\beta$ : Monomeric amyloid $\beta$; $\mathrm{NaCl}$ : Sodium chloride; Ntg: Nontransgenic; PBS: Phosphate-buffered saline; PBST: PBS-Triton X100; PK: Pharmacokinetics; SAPPa: Soluble alpha APP; SDSPAGE: Sodium dodecyl sulfate-polyacrylamide gel electrophoresis; tAß: Trimeric amyloid $\beta$; TBS: Tris-buffered saline; WT: Wild type
}

\section{Acknowledgements}

We thank Melissa Gonzalez Edick and Hai Ngu for acquiring and processing scanned florescent images from slides, Morgan Sheng for critical feedback on the manuscript, and Pam Chan and Mandy Kwong for assistance with PK analysis. Medical writing support for the development of this manuscript was provided by Meaghan Paganelli, PhD, and Liz LaFlamme, PhD, of Health Interactions, Inc., USA, and funded by F. Hoffmann-La Roche Ltd.

\section{Authors' contributions}

All authors provided substantial input into the design, data acquisition, and interpretation of the data for this analysis. In addition, all authors were involved in the development of the manuscript, including providing critical input, review, and approval of the final submitted version. All authors fully accept accountability for all aspects of this body of work, including ensuring that questions related to the accuracy, integrity, or any other part of the work are appropriately resolved.

\section{Funding}

This study was funded by F. Hoffmann-La Roche Ltd, Basel, Switzerland. Medical writing support for the development of this manuscript was provided by Meaghan Paganelli, PhD, and Liz LaFlamme, PhD, of Health Interactions, Inc., USA, and funded by F. Hoffmann-La Roche Ltd.

\section{Availability of data and materials}

Data sharing is not applicable to this article as no datasets were generated or analyzed during the current study.

\section{Ethics approval and consent to participate}

All animal experiments were approved by Genentech's Institutional Animal Care and Use Committee and comply with the Institute for Laboratory Animals' guidelines for the humane care and use of laboratory animals.

\section{Consent for publication}

Not applicable.

\section{Competing interests}

All authors are full-time employees of Genentech, Inc., and shareholders in F. Hoffmann-La Roche Ltd. The authors declare that they have no competing interests.

\section{Author details}

'Department of Neuroscience, Genentech, Inc., 1 DNA Way, South San Francisco, CA 94080, USA. ${ }^{2}$ Department of Preclinical and Translational Pharmacokinetics/Pharmacodynamics, Genentech, Inc., 1 DNA Way, South San Francisco, CA, USA. ${ }^{3}$ Department of Protein Chemistry, Genentech, Inc., 1 DNA Way, South San Francisco, CA, USA. ${ }^{4}$ Department of Biochemical and Cellular Pharmacology, Genentech, Inc., 1 DNA Way, South San Francisco, CA USA. ${ }^{5}$ Department of Safety Assessment Pathology, Genentech, Inc., 1 DNA Way, South San Francisco, CA, USA.

Received: 12 August 2019 Accepted: 6 November 2019 Published online: 01 December 2019

\section{References}

1. Selkoe DJ, Hardy J. The amyloid hypothesis of Alzheimer's disease at 25 years. EMBO Mol Med. 2016;8:595-608.

2. Haass C, Selkoe DJ. Soluble protein oligomers in neurodegeneration: lessons from the Alzheimer's amyloid beta-peptide. Nat Rev Mol Cell Biol. 2007;8: 101-12.

3. Benilova I, Karran E, De Strooper B. The toxic A oligomer and Alzheimer's disease: an emperor in need of clothes. Nat Neurosci. 2012;15:349-57.

4. Mucke L, Selkoe D. Neurotoxicity of amyloid $\beta$-protein: synaptic and network dysfunction. Cold Spring Harb Perspect Med. 2012;2:a006338.

5. Lesne S, Koh MT, Kotilinek L, Kayed R, Glabe CG, Yang A, et al. A specific amyloid-beta protein assembly in the brain impairs memory. Nature. 2006; 440:352-7.

6. Yang T, Li S, Xu H, Walsh DM, Selkoe DJ. Large soluble oligomers of amyloid $\beta$-protein from Alzheimer brain are far less neuroactive than the smaller oligomers to which they dissociate. J Neurosci. 2017;37:152-63.

7. Walsh DM, Selkoe DJ. A beta oligomers - a decade of discovery. J Neurochem. 2007;101:1172-84. 
8. Koffie R, Meyer-Luehmann M, Hashimoto T, Adams K, Mielke M, GarciaAlloza $M$, et al. Oligomeric amyloid $\beta$ associates with postsynaptic densities and correlates with excitatory synapse loss near senile plaques. Proc Natl Acad Sci U S A. 2009:106:4012-7.

9. Bittner T, Fuhrmann M, Burgold S, Ochs SM, Hoffmann N, Mitteregger G, et al. Multiple events lead to dendritic spine loss in triple transgenic Alzheimer's disease mice. PLoS One. 2010;5:e15477.

10. Ultsch M, Li B, Maurer T, Mathieu M, Adolfsson O, Muhs A, et al. Structure of crenezumab complex with $A \beta$ shows loss of $\beta$-hairpin. Sci Rep. 2016;6:39374.

11. Adolfsson O, Pihlgren $M$, Toni N, Varisco $Y$, Buccarello AL, Antoniello $K$, et al. An effector-reduced anti- $\beta$-amyloid $(A \beta)$ antibody with unique $A \beta$ binding properties promotes neuroprotection and glial engulfment of $A \beta$. J Neurosci. 2012;32:9677-89.

12. Wilcock DM, Alamed J, Gottschall PE, Grimm J, Rosenthal A, Pons J, et al. Deglycosylated anti-amyloid-beta antibodies eliminate cognitive deficits and reduce parenchymal amyloid with minimal vascular consequences in aged amyloid precursor protein transgenic mice. J Neurosci. 2006;26:5340-6.

13. Ostrowitzki S, Deptula D, Thurfjell L, Barkhof F, Bohrmann B, Brooks DJ, et al. Mechanism of amyloid removal in patients with Alzheimer disease treated with gantenerumab. Arch Neurol. 2012;69:198-207.

14. Salloway S, Sperling R, Gilman S, Fox NC, Blennow K, Raskind M, et al. A phase 2 multiple ascending dose trial of bapineuzumab in mild to moderate Alzheimer disease. Neurology. 2009;73:2061-70.

15. Fuller JP, Stavenhagen JB, Teeling JL. New roles for FC receptors in neurodegeneration-the impact on immunotherapy for Alzheimer's disease. Front Neurosci. 2014:8:235

16. Sevigny J, Chiao $P$, Bussière $T$, Weinreb $P H$, Williams $L$, Maier $M$, et al. The antibody aducanumab reduces $A \beta$ plaques in Alzheimer's disease. Nature. 2016;537:50-6.

17. Cummings $J$, Cohen S, Van Dyck CH, Brody M, Curtis C, Cho W, et al. ABBY: a phase 2 randomized trial of crenezumab in mild-to-moderate Alzheimer's disease. Neurology. 2018;90:e1889-97.

18. Ozmen L, Albientz A, Czech C, Jacobsen H. Expression of transgenic APP mRNA is the key determinant for beta-amyloid deposition in PS2APP transgenic mice. Neurodegener Dis. 2009;6:29-36.

19. Kallop DY, Meilandt WJ, Gogineni A, Easley-Neal C, Wu T, Jubb AM, et al. A death receptor 6-amyloid precursor protein pathway regulates synapse density in the mature CNS but does not contribute to Alzheimer's diseaserelated pathophysiology in murine models. J Neurosci. 2014;34:6425-37.

20. Feng G, Mellor RH, Bernstein M, Keller-Peck C, Nguyen QT, Wallace M, et al. Imaging neuronal subsets in transgenic mice expressing multiple spectral variants of GFP. Neuron. 2000;28:41-51.

21. Cai H, Wang $Y$, McCarthy $D$, Wen H, Borchelt DR, Price DL, et al. BACE1 is the major beta-secretase for generation of Abeta peptides by neurons. Nat Neurosci. 2001;4:233-4.

22. Salloway S, Honigberg LA, Cho W, Ward M, Friesenhahn M, Brunstein F, et al. Amyloid PET and CSF results from a crenezumab anti-amyloidbeta antibody double-blind, placebo-controlled, randomized phase ॥ study in mild-to-moderate Alzheimer's disease (BLAZE). Alzheimers Res Ther. 2018;10:96.

23. Holtzman DM, DeMattos R, Bales KR, Paul SM, Tsurushita N, Vasquez M: Humanized antibodies that sequester Abeta peptide. 20040043418. United States Patent Office. 2004, 10/226435(20040043418).

24. Esparza TJ, Wildburger NC, Jiang H, Gangolli M, Cairns NJ, Bateman RJ, et al. Soluble amyloid-beta aggregates from human Alzheimer's disease brains. Sci Rep. 2016;6:38187.

25. Wang W, Lu L, Wu QQ, Jia JP. Brain amyloid- $\beta$ plays an initiating role in the pathophysiological process of the PS1V97L-Tg mouse model of Alzheimer's disease. J Alzheimers Dis. 2016:52:1089-99.

26. Goure WF, Krafft GA, Jerecic J, Hefti F. Targeting the proper amyloid-beta neuronal toxins: a path forward for Alzheimer's disease immunotherapeutics. Alzheimers Res Ther. 2014;6:42.

27. Sakono M, Zako T. Amyloid oligomers: formation and toxicity of Abeta oligomers. FEBS J. 2010;277:1348-58.

28. DaRocha-Souto B, Scotton TC, Coma M, Serrano-Pozo A, Hashimoto T, Sereno $\mathrm{L}$, et al. Brain oligomeric $\beta$-amyloid but not total amyloid plaque burden correlates with neuronal loss and astrocyte inflammatory response in amyloid precursor protein/tau transgenic mice. J Neuropathol Exp Neurol. 2011;70:360-76.

29. van Dyck $\mathrm{CH}$. Anti-amyloid- $\beta$ monoclonal antibodies for Alzheimer's disease: pitfalls and promise. Biol Psychiatry. 2018;83:311-9.
30. Condello C, Yuan P, Schain A, Grutzendler J. Microglia constitute a barrier that prevents neurotoxic protofibrillar A 342 hotspots around plaques. Nat Commun. 2015;6:6176.

31. Mucke L, Masliah E, Yu GQ, Mallory M, Rockenstein EM, Tatsuno G, et al. High-level neuronal expression of abeta 1-42 in wild-type human amyloid protein precursor transgenic mice: synaptotoxicity without plaque formation. J Neurosci. 2000;20:4050-8.

32. Shankar GM, Li S, Mehta TH, Garcia-Munoz A, Shepardson NE, Smith I, et al. Amyloid-beta protein dimers isolated directly from Alzheimer's brains impair synaptic plasticity and memory. Nat Med. 2008;14:837-42.

33. Spires TL, Meyer-Luehmann M, Stern EA, McLean PJ, Skoch J, Nguyen PT, et al. Dendritic spine abnormalities in amyloid precursor protein transgenic mice demonstrated by gene transfer and intravital multiphoton microscopy. J Neurosci. 2005;25:7278-87.

34. Wu HY, Hudry E, Hashimoto T, Kuchibhotla K, Rozkalne A, Fan Z, et al. Amyloid beta induces the morphological neurodegenerative triad of spine loss, dendritic simplification, and neuritic dystrophies through calcineurin activation. J Neurosci. 2010;30:2636-49.

35. Meyer-Luehmann M, Spires-Jones TL, Prada C, Garcia-Alloza M, de Calignon A, Rozkalne A, et al. Rapid appearance and local toxicity of amyloid-beta plaques in a mouse model of Alzheimer's disease. Nature. 2008;451:720-4.

36. Sadleir KR, Kandalepas PC, Buggia-Prevot V, Nicholson DA, Thinakaran G, Vassar R. Presynaptic dystrophic neurites surrounding amyloid plaques are sites of microtubule disruption, BACE1 elevation, and increased A $\beta$ generation in Alzheimer's disease. Acta Neuropathol. 2016;132:235-56.

37. Ye $X$, Feng $T$, Tammineni $P$, Chang $Q$, Jeong $Y Y$, Margolis DJ, et al. Regulation of synaptic amyloid- $\beta$ generation through BACE1 retrograde transport in a mouse model of Alzheimer's disease. J Neurosci. 2017;37: 2639-55.

38. Claiborne BJ, Amaral DG, Cowan WM. A light and electron microscopic analysis of the mossy fibers of the rat dentate gyrus. J Comp Neurol. 1986; 246:435-58.

39. Amaral DG, Scharfman HE, Lavenex P. The dentate gyrus: fundamental neuroanatomical organization (dentate gyrus for dummies). Prog Brain Res. 2007; 163:3-22.

40. Frotscher M, Soriano E, Misgeld U. Divergence of hippocampal mossy fibers. Synapse. 1994;16:148-60.

41. Kandalepas PC, Sadleir KR, Eimer WA, Zhao J, Nicholson DA, Vassar R. The Alzheimer's beta-secretase BACE1 localizes to normal presynaptic terminals and to dystrophic presynaptic terminals surrounding amyloid plaques. Acta Neuropathol. 2013;126:329-52.

42. Coimbra JRM, Marques DFF, Baptista SJ, Pereira CMF, Moreira PI, Dinis TCP, et al. Highlights in BACE1 inhibitors for Alzheimer's disease treatment. Front Chem. 2018;6:178.

43. Kumar D, Ganeshpurkar A, Kumar D, Modi G, Gupta SK, Singh SK. Secretase inhibitors for the treatment of Alzheimer's disease: long road ahead. Eur J Med Chem. 2018;148:436-52.

44. Lao K, Ji N, Zhang X, Qiao W, Tang Z, Gou X. J Drug Target. 2019;27(2):16473. https://doi.org/10.1080/1061186X.2018.1474361. Epub 2018 Jun 20. PMID: 29732929

45. Agholme L, Clarin M, Gkanatsiou E, Kettunen P, Chebli J, Brinkmalm G, et al. Low-dose gamma-secretase inhibition increases secretion of Abeta peptides and intracellular oligomeric A 3 . Mol Cell Neurosci. 2017:85:211-9.

46. Bohrmann B, Baumann K, Benz J, Gerber F, Huber W, Knoflach F, et al. Gantenerumab: a novel human anti-A $\beta$ antibody demonstrates sustained cerebral amyloid-beta binding and elicits cell-mediated removal of human amyloid- $\beta$. J Alzheimers Dis. 2012;28:49-69.

47. Spires-Jones T, Meyer-Luehmann M, Osetek J, Jones P, Stern E, Bacskai B, et al. Impaired spine stability underlies plaque-related spine loss in an Alzheimer's disease mouse model. Am J Pathol. 2007:171:1304-11.

48. Masters CL, Selkoe DJ. Biochemistry of amyloid $\beta$-protein and amyloid deposits in Alzheimer disease. Cold Spring Harb Perspect Med. 2012;2: a006262.

49. Le Pichon CE, Meilandt WJ, Dominguez S, Solanoy $\mathrm{H}$, Lin $\mathrm{H}, \mathrm{Ngu} \mathrm{H}$, et al. Loss of dual leucine zipper kinase signaling is protective in animal models of neurodegenerative disease. Sci Transl Med. 2017;9. https://doi.org/10. 1126/scitrans/med.aag0394.

50. Fowler SW, Chiang AC, Savjani RR, Larson ME, Sherman MA, Schuler DR, et al. Genetic modulation of soluble $A \beta$ rescues cognitive and synaptic impairment in a mouse model of Alzheimer's disease. J Neurosci. 2014;34: $7871-85$. 
51. Chiang ACA, Fowler SW, Savjani RR, Hilsenbeck SG, Wallace CE, Cirrito JR, et al. Combination anti-A $\beta$ treatment maximizes cognitive recovery and rebalances mTOR signaling in APP mice. J Exp Med. 2018;215:1349-64.

52. Yuede $C M$, Lee $H$, Restivo $J L$, Davis $T A$, Hettinger JC, Wallace $C E$, et al. Rapid in vivo measurement of $\beta$-amyloid reveals biphasic clearance kinetics in an Alzheimer's mouse model. J Exp Med. 2016;213:677-85.

53. Abramowski D, Wiederhold KH, Furrer U, Jaton A-L, Neuenschwander A, Runser $\mathrm{M}-\mathrm{J}$, et al. Dynamics of A-beta turnover and deposition in different $\beta$-amyloid precursor protein transgenic mouse models following gammasecretase inhibition. J Pharmacol Exp Ther. 2008;327:411-24.

54. DiFrancesco JC, Longoni M, Piazza F. Anti-Aß autoantibodies in amyloid related imaging abnormalities (ARIA): candidate biomarker for immunotherapy in Alzheimer's disease and cerebral amyloid angiopathy. Front Neurol. 2015;6:207.

55. Bechten A, Wattjes MP, Purcell DD, Aliaga ES, Daams M, Brashear HR, et al. Validation of an MRI rating scale for amyloid-related imaging abnormalities. J Neuroimaging. 2017;27:318-25.

56. Sperling RA, Jack CR Jr, Black SE, Frosch MP, Greenberg SM, Hyman BT, et al. Amyloid-related imaging abnormalities in amyloid-modifying therapeutic trials: recommendations from the Alzheimer's Association Research Roundtable Workgroup. Alzheimers Dement. 2011;7:367-85.

57. Ostrowitzki S, Lasser RA, Dorflinger E, Scheltens P, Barkhof F, Nikolcheva T, et al. A phase III randomized trial of gantenerumab in prodromal Alzheimer's disease. Alzheimers Res Ther. 2017;9:95.

58. Sperling R, Salloway S, Brooks DJ, Tampieri D, Barakos J, Fox NC, et al. Amyloidrelated imaging abnormalities in patients with Alzheimer's disease treated with bapineuzumab: a retrospective analysis. Lancet Neurol. 2012;11:241-9.

59. Kastanenka KV, Bussiere T, Shakerdge N, Qian F, Weinreb PH, Rhodes K, et al. Immunotherapy with aducanumab restores calcium homeostasis in Tg2576 mice. J Neurosci. 2016;36:12549-58.

60. Yang T, Dang Y, Ostaszewski B, Mengel D, Steffen V, Rabe C, et al. Target engagement in an Alzheimer trial: Crenezumab lowers amyloid $\beta$ oligomers in cerebrospinal fluid. Ann Neurol. 2019;86(2):215-224. https://doi.org/10. 1002/ana.25513. Epub 2019 Jun 22. PMID: 31168802.

\section{Publisher's Note}

Springer Nature remains neutral with regard to jurisdictional claims in published maps and institutional affiliations.

Ready to submit your research? Choose BMC and benefit from:

- fast, convenient online submission

- thorough peer review by experienced researchers in your field

- rapid publication on acceptance

- support for research data, including large and complex data types

- gold Open Access which fosters wider collaboration and increased citations

- maximum visibility for your research: over $100 \mathrm{M}$ website views per year

At $\mathrm{BMC}$, research is always in progress.

Learn more biomedcentral.com/submissions 